\title{
The Effects on Instructor Workload of Implementing Active Teaching Methods to Improve Student Enthusiasm and Performance
}

\author{
Cory Mettler ${ }^{1}$ and Nathan Ziegler ${ }^{2}$ \\ ${ }^{1}$ Instructor, Electrical Engineering and Computer Science at South Dakota State \\ University (SDSU) - email: cory.mettler@sdstate.edu, ${ }^{2}$ Director, English \\ Language and Culture Institute at SDSU - email: nathan.ziegler@sdstate.edu
}

\begin{abstract}
There is an abundance of data that suggest that implementing active teaching methods in the classroom produces a deeper, longer lasting understanding and increased enjoyment of course material. However, most engineering educators do not employ these techniques. This paper addresses three of the most common concerns these educators have: 1. "I don't have enough time," 2. "It is difficult to employ active teaching techniques with my course material," and 3. "I won’t be able to cover all my material if I allow time for the activities in class.” .

Active teaching was employed in two courses in order to improve student enthusiasm for course material and increase understanding of that material. In each course, specific topics were taught using active teaching methods, while others were taught using traditional teaching methods. The active teaching methods employed were simple methods that were uncomplicated to prepare, often requiring less than five minutes of preparation per lecture. The effectiveness of these teaching methods was compared in three ways. First, students' non-verbal responses to the teaching methods were observed by an independent researcher trained in direct nonparticipation data collection. Both active and traditional lectures were observed using a modified rubric based on Ekman and Friesen's facial measurement system, which systematized and validated the observations. Second, students' test scores on topics taught by active teaching methods were compared to scores on topics taught by traditional methods. Third, students were surveyed on their perspective of the effectiveness of the active teaching methods. This data was compared to the time required to prepare these lectures and the amount of material covered.

Results show that, without fail, students were more engaged and scored higher on topics covered using simple active teaching methods as opposed to traditional lectures. Students' participation levels significantly increased during all aspects of lectures that included active teaching methods, including short periods of traditional lecture that followed the activity. Student surveys suggest that, although students' perception of active teaching methods was mixed to start the semester, the acceptance of these methods by the end of the semester had increased to $100 \%$ and many students desired more active opportunities. The amount of material covered in both classes increased from the previous course offering.
\end{abstract}




\section{Introduction}

There has been a significant amount of research on AT and its effectiveness in all aspects of education and there is an abundance of data that suggests AT methods are more effective methods of teaching than traditional lecturing ${ }^{1,2,4,5}$. However, as proven of a technique as it is, many technical educators still are resistant to implementing AT in their classrooms for a variety of reasons; these can include: "the notion that students must first master the underlying principles and theories of a discipline before being asked to solve substantive problems in that discipline $^{3}$, it requires too much effort to change existing course notes, and the class-time it takes to implement will reduce the amount of material that can be covered 4 .

The question addressed by this paper is: Can implementing active teaching techniques by only slightly modifying existing lecturing styles be effective in improving students' understanding of course material and increase student enthusiasm for the course?

Four outcomes of these modifications were assessed in this study:

1. Time spent on lesson planning will not increase by a significant amount.

2. The amount of course material must not decrease.

3. Student's mastery of the course material will increase.

4. Student enthusiasm for course material will be greater during Active Teaching classes.

\section{Background and Motivation}

This paper reports on the initial findings of one instructor's attempt to implement active teaching in his classes with the goal of improving upon his students' performance without significantly changing his workload. Throughout the course of one semester, the previously mentioned four outcomes were assessed to verify the change in teaching style was having a positive effect. This change in teaching style was implemented in the second semester of two class-sequences during the spring semester of 2014. The first semester of both class-sequences were taught using traditional lectures in the Fall of 2013. The instructor performing the study had 10 years of teaching experience, had taught both sophomore courses multiple times, and was preparing both junior courses for the first time. The sophomores enrolled in EE222 during Spring 2014 were the same students enrolled in EE220 during Fall 2013; similarly, juniors enrolled in EE321 during Spring 2014 were the same students enrolled in EE320 during Fall 2013. The term Active Teaching (AT) can be loosely defined by "any teaching method that does not include disseminating course material by traditional lecturing methods.” Examples of AT can include Project-Based Learning (PBL) ${ }^{1}$, Inductive Teaching (IT) ${ }^{5}$, or Cooperative Learning (CL) ${ }^{6}$. Often these methods require a significant effort to implement effectively. However, AT can also include activities that require much less effort on the instructor's part such as Thinking Aloud Peer Problem Solving (TAPPS) ${ }^{7}$ or small group discussion (SGD). 
Table 1 shows these 4 classes and compares the amount of times the instructor had taught each class in the past.

The term Active Teaching (AT) can be loosely defined by "any teaching method that does not include disseminating course material by traditional lecturing methods.” Examples of AT can include Project-Based Learning (PBL) ${ }^{1}$, Inductive Teaching $(\mathrm{IT})^{5}$, or Cooperative Learning (CL) ${ }^{6}$. Often these methods require a significant effort to implement effectively. However, AT can also include activities that require much less effort on the instructor's part such as Thinking Aloud Peer Problem Solving (TAPPS) ${ }^{7}$ or small group discussion (SGD).

Table 1. Courses used to assess the effectiveness of Active Teaching in this study

\begin{tabular}{|l|l|l|}
\hline & $\begin{array}{l}\text { Traditional Lecture (Fall } \\
\text { 2013) }\end{array}$ & $\begin{array}{l}\text { Active Teaching (Spring } \\
\text { 2014) }\end{array}$ \\
\hline Sophomore-level & $\begin{array}{l}\text { EE220: Circuits I } \\
\text { Previously Taught: 9 } \\
\text { semesters }\end{array}$ & $\begin{array}{l}\text { EE222: Circuits and } \\
\text { Machines Previously } \\
\text { Taught: 3 semesters }\end{array}$ \\
\hline Junior-level & $\begin{array}{l}\text { EE320: Electronics I } \\
\text { Previously Taught: 0 } \\
\text { semesters }\end{array}$ & $\begin{array}{l}\text { EE321: Electronics II } \\
\text { Previously Taught: 0 } \\
\text { semesters }\end{array}$ \\
\hline
\end{tabular}

Traditional Lecturing (TL) is characterized, for purpose of this study, by the instructor lecturing for the majority of the class period. This may include deriving equations, explaining definitions, and working problems. Delivery methods may include writing on whiteboards, providing notes via power point, and showing video clips or software simulations. The defining difference between AT and TL is the opportunity for student engagement. An instructor using TL limits the students' engagement to a few cold-call questions or volunteer opportunities during a lecture; this is where the instructor asks a question of the class and either cold-calls random students or waits for students to volunteer an answer. Of course, the instructor has good intentions of increasing class involvement, but the reality is that most students quickly advert their eyes in hopes they are not selected and only a few students, the same few every time, have an opportunity to engage. This is different than AT methods where the intent is to consistently achieve engagement from the entire class simultaneously; this way even the shy, introverted students who don't study outside the classroom are required to engage in the material and increase their learning potential.

\section{Methods}

During Spring 2014 semester, AT was implemented in the majority of the lectures for both EE222 and EE321. However, a handful of intentionally chosen lectures were still taught with TL in both courses. This was done to compare students' mastery of course material when taught using the two different methods. In the lectures where AT was implemented, three primary 
methods of AT were used: TAPPS, SGD, and Individual Sketch (IS). The first two were group activities, and the third required individual effort.

A Thinking Aloud Pair Problem Solving (TAPPS) exercise is a teaching method where the instructor provides a worked-out example to the students. Students form groups, typically of two students, and one student is chosen to be the group leader. The group leader's job is to walk through the example and verbally explain, in detail, each of the steps in the example. The remaining student's job is to question the leader as much as possible and if a question arises that the leader cannot answer the group works together to answer the question. A number of interesting variations to this method were implemented as well. Some of the examples were not completed and the student groups were required to determine a missing equation or calculate some value in order to finish the example. Some examples were provided to the students with mistakes intentionally left in the example and the students were required to find the mistakes. Sometimes the instructor determined the group leaders, other times the students were allowed to nominate a leader. The examples used for these activities were the same examples the instructor would have personally presented in a TL; however, by allowing the students to work through the example individually, the students were forced to engage the example at a deeper level.

Small Group Discussions (SGD) were also used on a regular basis and implemented in a variety of ways. Typically, the instructor would pose a question during lecture, but rather than wait for a single student to volunteer an answer, the class would be instructed to "discuss your thoughts with the student sitting next to you." Then, when sufficient time passed, the class was reconvened and a few groups were called on to provide answers. This method gave every student in class an opportunity to voice thoughts about the question posed rather than limiting engagement to one or two eager volunteers. Another benefit of this method is that it allows students who prefer to take a little extra time to formulate an answer the time to do so before they are put on the spot in front of classmates; this makes the classroom environment more comfortable to those students. Yet another benefit is that if a student would not know the answer to the question and they are, by chance, called upon, they can rely on the group's discussion to provide an answer; this again improves the comfort level of the students. The questions asked for these activities were the same questions the instructor would have historically used for coldcalling in a TL.

Individual Sketch (IS) was also used. A question was posed to the students similar to SGD questions, but rather than form groups, the students were asked to write their own answers individually. Typically, the instructor would provide the correct answer rather than call on students for answers.

The four desired Outcomes of this study were assessed in the following ways:

Outcome \#1: The amount of preparation time required to implement AT methods was assessed by simply monitoring the amount of time spent on preparing each lecture in EE222 and EE321 
and comparing that to the same data collected from EE220 and EE320, respectively. The criterion for successful implementation of AT methods for this category was an increase of preparation time of no more than 15 minutes per lecture.

Outcome \#2: The material covered in EE222 and EE321 was determined by the historical record of these two classes. Detailed semester schedules were determined before the start of the semester and were strictly adhered to so that the change in teaching style would not cause the students to fall behind in their course work. The criterion for successful implementation of AT methods for this category was no topics traditionally taught were missed.

Outcome \#3: Student mastery of the course material was assessed by analyzing student grades in two ways. On the three semester tests in both classes, questions were posed where the skill being assessed was specifically taught using an AT method and questions were posed where the skill being assessed was specifically taught using TL. Student performance on the two categories was compared. Class averages in EE222 and EE321 during Spring 2014 were compared to class averages in EE220 and EE320 during Fall 2013. While individual student grades were not assessed, only students enrolled in both courses (EE220 and EE222 or EE320 and EE321) were used to assess these grades. The class average in EE222 during Spring 2014 was also compared to the class averages of previous EE222 classes taught by the same instructors. This same comparison could not be made for EE321 since the instructor had not previously taught EE321 and a direct comparison against another instructor's grades did not appear to be a valid assessment of AT.

The first criterion for successful implementation of AT methods for this category was that students scored higher on test problems assessing skills which were taught using AT than they did on skills which were taught using TL. The second criterion for successful implementation of AT methods for this category was that the class average of EE222 remained statistically insignificant from the class average of EE220 and that the class average of EE321 remained statistically insignificant from the class average of EE320. It was decided to consider no change in these comparisons a success because the material taught in EE222 and EE321 is respectively more challenging than the material in EE220 and EE320 and class averages typically drop in the second course of the sequences. The third criterion for successful implementation of AT methods for this category was that the class average of EE222 during Spring 2014 increased from the class averages of EE222 during Spring 2013 and 2012.

Outcome \#4: Student enthusiasm for the course material is a much more difficult outcome to assess so, a number of assumptions were made in order to do so. First, it was assumed that class participation would increase if students were more enthusiastic about the course material. Second, it was assumed that students would develop more in-depth, application-based questions about the course material if students were more enthusiastic about the course material. Third, students who personally see an educational benefit to classroom activities are more likely to be enthusiastic than students who do not. 
A number of tools were used to assess the students for this outcome. First, the instructor monitored class participation during cold-call questions in TL and during activities in AT methods using the rubric in Table 2. Class participation was assessed during the question or activity and again immediately after reconvening. Also, the number of times a question or activity resulted in the students asking an in-depth follow-on question (as opposed to a clarification question) was monitored.

The second tool used were minute papers where the students were questioned three times during the semester about their thoughts on AT. Students were asked to state whether they thought AT improved their knowledge of the course material.

Table 2. Rubric used in class to gage student participation

\begin{tabular}{|l|l|l|l|l|ll|}
\hline Activity: & 1 & 2 & 3 & 4 & 5 Y/N \\
\hline $\begin{array}{l}\text { Class participation during } \\
\text { activity: }\end{array}$ & 1 & 2 & 3 & 4 & $5 \quad$ Y/N \\
\hline $\begin{array}{l}\text { Class participation after } \\
\text { reconvening: }\end{array}$ &
\end{tabular}

where,

1. No class participation

2. Participation by only a small core group of commonly active students

3. Participation by more than $50 \%$ of students

4. Participation by more than $90 \%$ of students

5. Activity resulted in extended discussion (yes or no)

The third method used to assess students' enthusiasm occurred through direct observations of classroom engagement. An independent researcher observed six classroom lectures, three that used AT and three that used TL. The researcher sat in the classroom in the front corner. To prevent a Hawthorne-effect ${ }^{8}$, the researcher collected unofficial data in two lectures prior to actual data collection, sitting in the same location. While not eliminating the Hawthorne-effect, it is reasonable to assume that students became accustomed to the researcher sitting in the classroom. During the observation, the researcher observed participants facial expressions, systematically observing all students in the class two to four times within one class period. Using the adapted rubric ${ }^{9}$ the researcher recorded students' facial movements, assigned each participant a valence mark (positive or negative emotional state), identified the type of expression they were displaying (i.e., Enthusiasm, Boredom, Sadness, Happiness, Frustration, Fear, Amusement, and Disgust), and then assigned each expression a level of intensity (i.e., 1=low, 2=Fairly low, 3=Medium, 4=Fairly High, 5=High, 6=Very High). Field notes were also collected to aid in the interpretation of data.

The first criterion for successful implementation of AT methods for this category was that class participation, as monitored by the rubric in Table 2, was higher during AT activities than TL, that the level of participation during AT reached $90 \%$ of the class during at least $75 \%$ of the 
activities, and that AT activities generated follow-up questions twice as often as TL. The second criterion for successful implementation of AT methods for this category was that over $80 \%$ of the students responded positively to AT by the end of the semester. The final criterion for successful implementation of AT methods for this category was that the independent researcher would observe a statistical relationship between higher levels of enthusiasm and Active Teaching.

\section{Data Analysis and Results}

The results of the assessment of the four outcomes are as follows:

Outcome \#1: Table 3 shows the average amount of preparation time required for each lecture in the Circuits and Electronics sequences. The instructor had previously prepared the Circuits sequence (EE220 and EE222) and, so, the active teaching modifications simply required a wording or formatting change to the previously prepared notes. The instructor was creating new material for the first time in the Electronics sequence (EE320 and EE321), so significantly more time was required to prepare for each lecture as compared to the 200-level courses. Examples and in-class questions had to be created from scratch and sometimes revised. EE321 required, on average, 14.4 minutes more to prepare than EE320.

Table 3. Average time required to prepare lectures

\begin{tabular}{|c|c|c|c|c|c|}
\hline Class & $\begin{array}{c}\text { Semesters } \\
\text { taught }\end{array}$ & $\begin{array}{l}\text { Num of } \\
\text { Lectures }\end{array}$ & $\begin{array}{c}\text { Req Prep } \\
\text { per lecture } \\
\text { in } 2013 / 14 \\
\text { (min) } \\
\end{array}$ & $\begin{array}{c}\text { Total Prep } \\
\text { Time in } \\
\text { 2013/14 } \\
\text { (hr) } \\
\end{array}$ & $\begin{array}{c}\text { Increased } \\
\text { time to } \\
\text { prep } \\
\text { (min) } \\
\end{array}$ \\
\hline EE220 & 9 & 30 & 18.8 & 9.4 & \multirow{2}{*}{6.4} \\
\hline EE222 & 3 & 32 & 25.2 & 13.4 & \\
\hline EE320 & 0 & 24 & 137.3 & 54.9 & \multirow{2}{*}{13.4} \\
\hline EE321 & 0 & 22 & 150.7 & 55.3 & \\
\hline
\end{tabular}

The active teaching modifications took nearly no extra effort on the instructor's part to implement. The course which had been previously prepared, EE222, required an average of 6.4 minutes of additional preparation for the AT lectures as compared to the related course which had been taught by traditional lectures, EE220. The majority of this increase was due to the need to reformat lecture notes, but required no higher level cognitive processing (the effort was mostly copy/paste or rewording in the instructor's notes). The new course, EE321, required an average of 13.4 minutes of additional preparation time as compared to its related course, EE320. The majority of this increase was due to the effort of anticipating student errors on particular example problems - this level of effort was not required in EE222 since the instructor already had notes on typical errors for that material from his previous experience teaching the course. 
Outcome \#2: The goal was to cover the same amount of material in both courses in which AT was implemented. EE222 and EE321 topics covered during Spring 2013 and Spring 2014 are compared in Table 4. In both classes students were able to cover the same material in less time and the change to AT actually allowed for more topics to be covered. The number of examples of each topic either increased or remained the same.

One of the biggest differences perceived by the instructors was that students were able to read through TAPPS exercises faster than the instructor could verbally discuss the same problem. However, students were able to individually focus more effort in their specific weakness making the time spent more efficient. AT in general seemed to allow the students to learn the material better the first time through requiring less (or faster) review of material previously covered.

Table 4. Topics covered in EE222 and EE321 during the Spring 2013 and 2014 semesters

\begin{tabular}{|c|c|c|c|}
\hline \multicolumn{2}{|c|}{ EE222: Circuits and Machines topics } & \multicolumn{2}{|c|}{ EE321: Electronics II topics } \\
\hline 2013 & 2014 & 2013 & 2014 \\
\hline $\begin{array}{l}\text { Sinusoidal Steady } \\
\text { State }\end{array}$ & $\begin{array}{l}\text { Sinusoidal Steady } \\
\text { State }\end{array}$ & $\begin{array}{l}\text { Frequency response } \\
\text { of transistors }\end{array}$ & $\begin{array}{l}\text { Frequency response } \\
\text { of transistors }\end{array}$ \\
\hline $\begin{array}{l}\text { Phasors and } \\
\text { Impedance }\end{array}$ & $\begin{array}{l}\text { Phasors and } \\
\text { Impedance }\end{array}$ & $\begin{array}{l}\text { Integrated Circuit } \\
\text { transistor designs }\end{array}$ & $\begin{array}{l}\text { Integrated Circuit } \\
\text { transistor designs }\end{array}$ \\
\hline $\begin{array}{l}\text { Complex and } \\
\text { Apparent Power }\end{array}$ & $\begin{array}{l}\text { Complex and } \\
\text { Apparent Power }\end{array}$ & Current sources & Current sources \\
\hline 3phase circuits & 3phase circuits & $\begin{array}{l}\text { Differential } \\
\text { amplifiers }\end{array}$ & $\begin{array}{l}\text { Differential } \\
\text { amplifiers }\end{array}$ \\
\hline $\begin{array}{l}\text { Magnetically } \\
\text { coupled circuits }\end{array}$ & $\begin{array}{l}\text { Magnetically } \\
\text { coupled circuits }\end{array}$ & Active loads & Active loads \\
\hline Transformers & Transformers & ---- & Feedback \\
\hline $\begin{array}{l}\text { S-domain circuit } \\
\text { analysis }\end{array}$ & $\begin{array}{l}\text { S-domain circuit } \\
\text { analysis }\end{array}$ & CMOS OpAmps & CMOS OpAmps \\
\hline $\begin{array}{l}\text { DC motors and } \\
\text { generators }\end{array}$ & $\begin{array}{l}\text { DC motors and } \\
\text { generators }\end{array}$ & $\begin{array}{l}\text { Logic Inverters and } \\
\text { Gates }\end{array}$ & $\begin{array}{l}\text { Logic Inverters and } \\
\text { Gates }\end{array}$ \\
\hline Induction Motors & Induction Motors & Memory Circuits & Memory Circuits \\
\hline--- & $\begin{array}{l}\text { Elect to Mech } \\
\text { system conversions }\end{array}$ & & Oscillators \\
\hline
\end{tabular}

Outcome \#3: Class averages on test problems that assessed skills taught using an AT method were compared to averages on problems that assessed skills taught using TL. Table 5 compares the EE222 questions and

Table 6 compares EE321 questions. The questions labeled ATx correspond to questions labeled TLx; meaning that the two questions are approximately worth the same number of points and all effort was made to make the two questions about the same difficulty level, as often as possible the two questions related to the same problem. Every skill assessed was covered by the instructor in lecture with approximately the same amount of class time dedicated to the skill 
taught by AT as dedicated to the skill taught with a TL. All skills assessed where listed on a study guide provided to the students prior to taking the test so the students had to expect skills taught by both methods to be assessed on the test.

Students' average score was higher on every skill taught by AT methods as compared to the corresponding skill taught by TL and the overall average on AT questions was higher by 18.5\% in EE222 and by 12.4\% in EE321. It is possible that there are contributing factors besides AT that inflated the AT skills; these possibilities will be addressed in the Study Limitations section below. Regardless, it is clear from this data that this particular group of students mastered skills taught by active teaching methods at a much higher level than skills taught by traditional lectures.

Table 5. Comparison of EE222 test questions

\begin{tabular}{|c|c|c|c|}
\hline & Test Question & Possible points & Class average \\
\hline AT1 & $\begin{array}{l}\text { Determine the current produced in this circuit and predict how } \\
\text { it will change if the frequency is reduced }\end{array}$ & 6 & $61.1 \%$ \\
\hline AT2 & $\begin{array}{l}\text { Find the apparent power from this } 3 \text { phase source, use the } \\
\text { power triangle to describe pf correction }\end{array}$ & 40 & $76.9 \%$ \\
\hline AT3 & $\begin{array}{l}\text { Draw a model of this circuit that accounts for the mutual } \\
\text { coupling }\end{array}$ & 10 & $83.3 \%$ \\
\hline AT4 & Reflect the load and/or source over the ideal transformers & 15 & $72.0 \%$ \\
\hline AT5 & $\begin{array}{l}\text { Write the system of equations for this circuit with initial } \\
\text { conditions using S-domain analysis to determine the mesh } \\
\text { currents }\end{array}$ & 20 & $85.3 \%$ \\
\hline AT6 & Determine the induced voltage on this DC motor & 10 & $96.4 \%$ \\
\hline \multirow[t]{2}{*}{ AT7 } & Translate this ME model to an EE equivalent & 30 & $56.2 \%$ \\
\hline & Average AT test score & & $74.1 \%$ \\
\hline TL1 & $\begin{array}{l}\text { Draw a phasor diagram of the signals at } 60 \mathrm{~Hz} \text { and explain how it } \\
\text { changes at } 50 \mathrm{~Hz}\end{array}$ & 8 & $38.2 \%$ \\
\hline TL2 & $\begin{array}{l}\text { Determine the RMS value of a sawtooth wave and find the } \\
\text { resistance that draw the max power from this circuit }\end{array}$ & 30 & $45.7 \%$ \\
\hline TL3 & Write the KVL equation for the mutually coupled model & 10 & $75.3 \%$ \\
\hline TL4 & Analyze the currents in the ideal transformer circuit & 10 & $68.0 \%$ \\
\hline TL5 & Solve the system of equations using Cramer's Rule & 10 & $64.7 \%$ \\
\hline TL6 & Determine the induced current on this DC motor & 10 & $90.0 \%$ \\
\hline \multirow[t]{2}{*}{ TL7 } & Determine the speed and torque of this DC motor & 40 & $47.7 \%$ \\
\hline & Average TL test score & & $55.6 \%$ \\
\hline
\end{tabular}

Table 6. Comparison of EE321 test questions 


\begin{tabular}{|c|c|c|c|}
\hline & Test Question & Possible points & Class average \\
\hline AT1 & Determine W/L of this MOSFET current source & 10 & $85.3 \%$ \\
\hline AT2 & Design a MOSFET current steering circuit & 20 & $95.8 \%$ \\
\hline AT3 & $\begin{array}{l}\text { Determine the required drain resistance and offset voltage for } \\
\text { this differential amplifier }\end{array}$ & 25 & $80.2 \%$ \\
\hline \multirow[t]{2}{*}{ AT4 } & Implement this logic statement & 25 & $56.7 \%$ \\
\hline & Average AT test score & & $77.4 \%$ \\
\hline TL1 & Determine VSD for this MOSFET current source & 10 & $77.5 \%$ \\
\hline TL2 & Design a BJT current steering circuit & 10 & $60.8 \%$ \\
\hline TL3 & $\begin{array}{l}\text { Determine the } W / L \text { ratio and common mode gain for this } \\
\text { differential amplifier }\end{array}$ & 25 & $71.8 \%$ \\
\hline \multirow[t]{2}{*}{ TL4 } & Size the transistors for this logic gate & 25 & $55.0 \%$ \\
\hline & Average TL test score & & $65.0 \%$ \\
\hline
\end{tabular}

Both classes' overall semester grades were also compared to the same group of student's semester grades from the previous class. These comparisons are organized into Error! Not a valid bookmark self-reference.. When comparing the exact same group of students in the Electronics sequence (row 1), the class averages improved slightly, but are statistically the same. This was what was expected and suggests that this group of students mastered harder material of Electronics II to the same level as the easier material of Electronics I.

However, when comparing the class averages of the Circuits students (row 2), there was a 5.8\% drop in grades. Upon further analysis, it was noticed that the EE220-Fall2013 class average was 9.3\% higher than the average grades in EE220 from the previous two EE220 course offerings and the EE222-Spring2014 class average was 12.7\% higher than the EE222 average grades from the previous two EE222 course offerings. Row 3 of Error! Not a valid bookmark selfreference. shows that the average drop in grades between EE220 and EE222 is 9.2\%. The drop in grades in Spring 2014, after AT was implemented, was 3.4\% smaller than the average, this is a 58.6\% improvement. Furthermore, the EE222 class average in Spring2014 was 12.7\% higher than the average over the previous semesters. So, while AT did not have as much effect on this class as originally hoped, the data does suggest that AT did increase this group of student's understanding of course material as compared to previous groups of students.

Table 7. Comparison of semester grades

\begin{tabular}{|l|l|l|l|c|}
\hline Class \#1 & $\begin{array}{l}\text { Grade } \\
\# 1\end{array}$ & Class \#2 & $\begin{array}{l}\text { Grade } \\
\# 2\end{array}$ & Difference \\
\hline \hline EE320-Fall2013 & $78.8 \%$ & EE321-Spring2014 & $80.1 \%$ & $1.3 \%$ \\
\hline EE220-Fall2013 & $91.7 \%$ & EE222-Spring2014 & $85.9 \%$ & $-5.8 \%$ \\
\hline EE220-2011\&2012 & $82.4 \%$ & EE222-2012\&2013 & $73.2 \%$ & $-9.2 \%$ \\
\hline
\end{tabular}

Outcome \#4: Three tools were used to assess student enthusiasm for the course. 
Operating off the assumption that students who are more actively engaged in lecture are more enthusiastic about the material being presented, the instructor monitored the engagement level of the class during each of four types of in-class activities. The rubric in Table 2 was used to evaluate the class participation. Table 8 displays these results for the two courses. When asked to work on a problem in groups using with the TAPPS or SGD activities, class engagement was at a level 4 (more than 90\% of the class actively engaged) 79.3\% (in EE222) and 88.1\% (in EE321) of the time. Contrast this with the class engagement during cold calls. In the EE321 class, $90 \%$ of cold calls resulted in level 1 or 2 (either no participation or participation from only the small core group of students, 2 or 3 students at the most) and cold calls never generated participation from more than the core group in EE222. Table 8 also shows that participation remained high in both classes immediately after an AT activity when a group discussion was appropriate, whereas this opportunity was not even possible after a Cold-Call. A further note, SGD and TAPPS generated student follow-up questions after 29.2\% (in EE222) and 44.4\% (in EE321) of the activities, whereas cold calls only generated follow-up questions after $18.1 \%$ (in EE222) and 10.0\% (in EE321) of the activities. This strongly suggests that cold calls prevent students the opportunity of deeper level thinking about a topic.

Table 8. Amount of class participation achieved after specific in-class activities

\begin{tabular}{|c|c|c|c|c|c|c|}
\hline \multicolumn{2}{|c|}{ EE222 Activities } & 1 & 2 & 3 & 4 & 5 \\
\hline \multirow[t]{2}{*}{ Small groups } & During & 0 & 0 & 5 & 17 & 3 \\
\hline & After & 0 & 1 & 5 & 14 & 3 \\
\hline \multirow[t]{2}{*}{ TAPPS } & During & 0 & 0 & 1 & 6 & 1 \\
\hline & After & 0 & 0 & 1 & 3 & 4 \\
\hline \multirow[t]{2}{*}{ Ind. Sketch } & During & 0 & 1 & 2 & 1 & 0 \\
\hline & After & 0 & 0 & 3 & 1 & 1 \\
\hline Cold Calls & During & 5 & 6 & 0 & 0 & 2 \\
\hline \multicolumn{2}{|c|}{ EE321 activities } & 1 & 2 & 3 & 4 & 5 \\
\hline \multirow[t]{2}{*}{ Small groups } & During & 0 & 0 & 5 & 25 & 2 \\
\hline & After & 0 & 1 & 7 & 11 & 9 \\
\hline \multirow[t]{2}{*}{ TAPPS } & During & 0 & 0 & 0 & 12 & 0 \\
\hline & After & 1 & 0 & 2 & 5 & 3 \\
\hline \multirow[t]{2}{*}{ Ind. Sketch } & During & 0 & 0 & 1 & 1 & 0 \\
\hline & After & 0 & 0 & 2 & 0 & 0 \\
\hline Cold Calls & During & 8 & 10 & 1 & 1 & 2 \\
\hline
\end{tabular}

Students were polled three times to assess their level of acceptance to the change in styles. Table 9 shows the number of students who responded positively to questions about AT in each of the 
three minute papers. As can be seen, student acceptance of AT significantly increased throughout the semester until $100 \%$ of the students in both classes agreed that AT was helping their education. In fact, on a follow up question on paper \#3, students were asked if the amount of AT was: Too Much, Just Right, Not Enough. 50\% of EE321 students and 69\% of EE222 students stated the amount was Not Enough and should be increased; the remaining students in both classes stated the amount was Just Right.

Table 9. Amount of students who positively responded to questioning about AT.

\begin{tabular}{|l|l|l|l|}
\hline & $\begin{array}{l}\text { Minute } \\
\text { Paper \#1 }\end{array}$ & $\begin{array}{l}\text { Minute } \\
\text { Paper \#2 }\end{array}$ & $\begin{array}{l}\text { Minute } \\
\text { Paper \#3 }\end{array}$ \\
\hline EE222 & $68.7 \%$ & $81.3 \%$ & $100 \%$ \\
\hline EE321 & $70.0 \%$ & $70 \%$ & $100 \%$ \\
\hline
\end{tabular}

The third prediction was that students would exhibit more enthusiasm during the AT classes than during the TL classes. Results for this measurement were threefold. First, there was significant correlation between some observed behaviors, perceived expression, and intensity. For example, the most common behavior observed, Eye Brow Raising (whole) was correlated with perceived enthusiasm (Chi-square $=12.911 ; \mathrm{p}<.05$ ) when the intensity of that expression was very high. This suggests that there was internal consistency with the observation of participants and the perceived expressions. Second, results showed that there was some correlation between Teaching Style and Expression (Pearson=.138; $<<.05$ ), and Teaching Style and Intensity of Expression (Pearson=-.435; $\mathrm{p}<.01$ ). Table 10 shows the frequency of the occurrences. "Fairly Low Enthusiasm” occurred 29 times during TL, but only 4 times during AT. This is drastically contrasted with 65 occurrences of "Very High Enthusiasm" during AT and only 9 occurrences during TL. This data suggests that the group of students observed were naturally motivated students who were enthusiastic about the course material in general; however, during times of AT, that level of enthusiasm increased significantly.

Third, results from an ANOVA test showed there was a significant relationship between higher levels of enthusiasm and Active Teaching ( $\mathrm{F}=69.370 ; \mathrm{p}<.01)$. More specifically, students demonstrated enthusiasm for during both methods, but the level of intensity was far greater for the Active Teaching than it was for the Traditional Lecture, Fig 1. Very few participants demonstrated boredom during any of the classes. However, boredom was only observed in the Traditional Lecture. These results suggest that students were significantly more engaged and enthusiastic during the Active Teaching classes than the Traditional Lecture.

\section{Study Limitations}

The observations conducted by the independent researcher could have two limitations. Firstly, participants' behavior could have been different because of the presence of the researcher during the observation, known as the Hawthorne Effect ${ }^{8}$. This may be important when considering the overall level of enthusiasm for both teaching methods. Because the researcher was there equal amounts of time (3 AT classes and 3 TL classes), the comparison of the data should be valid 
despite this effect. Secondly, the researcher's observations may influenced by his own bias, the Halo Effect ${ }^{10}$. That is, because the researcher was looking for enthusiasm, his perception of the behaviors could have been influenced by this bias. However, the researcher recorded all of the physical behaviors and found a relationship between perceived expression and non-verbal physical behaviors, thus minimizing the Halo Effect.

Another limitation of this study may have been the fact that the students knew that the different teaching styles were being evaluated. This may have inadvertently led the students to believe topics covered by active teaching methods were more important and, therefore, more likely to be covered on tests. The difference between student-achievement on AT-taught skills versus TLtaught skills was the most drastic on Test 1 in both classes studied. The difference on Test 2 and Test 3 decreased, suggesting that the students corrected this misconception after the first test. No attempt has been made in this study to quantify the increase in achievement caused by AT, this study's claim is simply that achievement level did in fact increase.

Table 10. Frequency of Teaching Style, Expression, and Intensity of Expression

\begin{tabular}{|c|c|c|c|c|c|}
\hline \multirow[b]{2}{*}{ Intensity } & & & \multicolumn{2}{|c|}{ TeachingStyle } & \multirow[b]{2}{*}{ Total } \\
\hline & & & $\begin{array}{c}\text { Active } \\
\text { Teaching }\end{array}$ & $\begin{array}{c}\text { Traditional } \\
\text { Lecture }\end{array}$ & \\
\hline \multirow[t]{2}{*}{ Low } & Expression & Enthusiasm & 2 & 3 & 5 \\
\hline & Total & & 2 & 3 & 5 \\
\hline \multirow[t]{2}{*}{ Fairly Low } & Expression & Enthusiasm & 4 & 29 & 33 \\
\hline & Total & & 4 & 29 & 33 \\
\hline \multirow[t]{3}{*}{ Medium } & Expression & Enthusiasm & 26 & 43 & 69 \\
\hline & & Bored & 2 & 6 & 8 \\
\hline & Total & & 28 & 49 & 77 \\
\hline \multirow[t]{2}{*}{ Fairly High } & Expression & Enthusiasm & 13 & 18 & 31 \\
\hline & Total & & 13 & 18 & 31 \\
\hline \multirow[t]{4}{*}{ High } & Expression & Enthusiasm & 49 & 18 & 67 \\
\hline & & Bored & 0 & 2 & 2 \\
\hline & & Frustration & 1 & 0 & 1 \\
\hline & Total & & 50 & 20 & 70 \\
\hline \multirow[t]{3}{*}{ Very High } & Expression & Enthusiasm & & 9 & 74 \\
\hline & & Bored & 0 & 10 & 10 \\
\hline & Total & & 65 & 19 & 84 \\
\hline
\end{tabular}

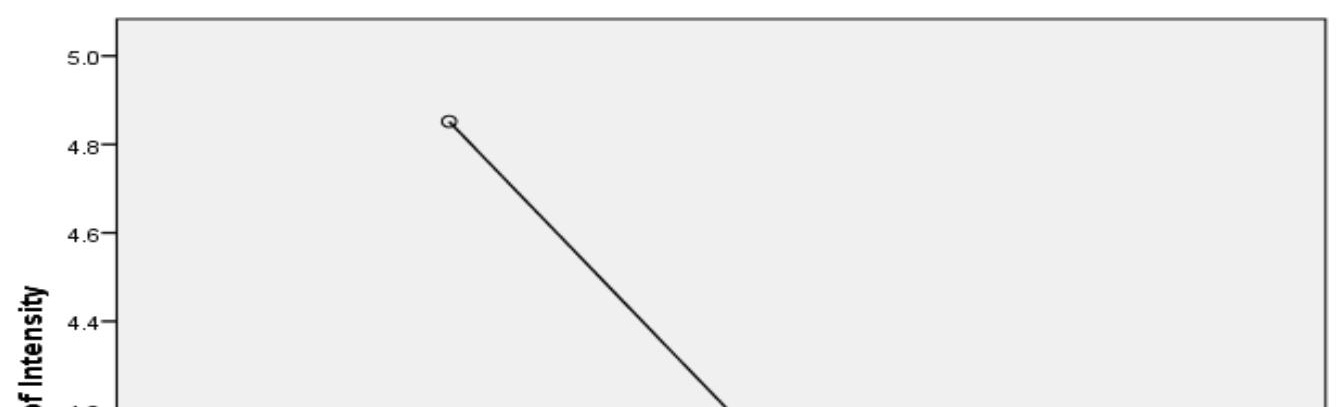


Fig 1. Mean Intensity of Active Teaching vs. Lecture Teaching (scale of 1:6) A fourth limitation of this study was the small sample size of students available. An attempt to mitigate this limitation was made by performing the study in two classes simultaneously. The confidence of this study will continue to increase as this approach is studied over the next few semesters; at that point, the historical averages of a large number of students can be compared.

\section{Conclusions}

This study showed a successful implementation of Active Teaching for all criteria for the four desired outcomes. The amount of increased preparation time required to implement AT methods proved to be insignificant, less than 15 minutes per lecture. The amount of material covered in both classes actually increased compared to previous offerings of the same course; this result was better than expected at the onset of the study. Student engagement and enthusiasm was shown to be significantly higher during AT than during TL and the more the students were exposed to AT, the more they accepted it and recognized it as beneficial to their education. All criteria for outcomes 1, 2, and 4 were unquestionably reached.

For Outcome \#3, three criteria were used to assess the implementation of AT. The first and third criterions for this outcome were undoubtedly surpassed; students in both classes scored higher on skills taught by AT methods than by TL methods and students in EE222 during Spring 2014 scored higher than EE222 students from the previous semesters. The remaining criterion for this outcome was that students would master the second-level course at the same level as the firstlevel course of each sequence. EE321 students did, in fact, master the harder material at the same level as the easier material. Unfortunately, the EE222 students average dropped compared to that group of students' EE220 class average. However, a large drop in student average should have been expected. The Spring 2014 students' average dropped by less than $40 \%$ of the historical drop. This suggests that the EE222 students did not learn their material as well as the EE220 material, but that they did significantly improve upon previous EE222 student 
performance. While this part of this criterion was not as successful as initially desired, it should still be considered a success.

This study shows that students demonstrate more enthusiasm when taught with the Active Teaching method in comparison with the Traditional Lecture method. This points to the need to have engaging curriculum that encourages active participation and a richer dialog between the students and the teacher during the class time. Students who demonstrate more enthusiasm will have more self-efficacy and motivation to perform better throughout the course ${ }^{11}$. More profoundly, this study shows that the effort required by the instructor to implement Active Teaching can be minimal and yet still effective, and does not have to affect the amount of course material covered. Overall, this study showed that implementing active teaching techniques by only slightly modifying existing lecturing styles can be extremely effective in improving students' understanding of course material and increase student enthusiasm for the course without significantly affecting the instructor's workload.

\section{Bibliography}

1. J. Amador, L. Miles and C. Peters, "The practice of Problem Based Learning: A Guide to implementing PBL in the College Classroom," San Francisco: Jossey-Bass., 2007.

2. J. Thomas, "A review of research on project-based learning," San Rafael, CA: Autodesk Foundation. University of Delaware Problem based Learning Website.

3. R. Felder and M. and Prince, "The Case for Inductive Teaching," ASEE Prism, vol. 55, 2007.

4. Interview

5. M. Prince and R. and Felder, "Inductive teaching and learning methods: Definitions, comparisions, and research basis," J. Engr. Education, vol. 95, no. 2, pp. 123-138, 2006.

6. R. Felder and R. Brent, "Cooperative learning in technical courses: Procedures, pitfalls, and payoffs.," National Science Foundation, 1994.

7. M. Pate and G. and Miller, "Effects of Think-Aloud Pair Problem Solving on Secondary-Level Students' Performance in Career and Technical Education Courses," J. Agriculture Education, vol. 52, no. 1, pp. 120-131, 2011.

8. D. M. Mertens, "Research and Evaluation in Education and Psychology," Thousand Oaks, California: Sage, 2010.

9. P. Ekman and W. V. Friesen, The Facial Action Coding System, Palo Alto, CA: Consulting Psychological Press., 1978.

10. R. E. Nisbett and T. D. Wilson, "1977," Journal of Personality and Social Psychology, vol. 35, no. 4, pp. 250256, 1977.

11. B. J. Zimmerman and J. Ringle, "Effects of model persistence and statements of confidence on children's selfefficacy and problem solving," Journal of Educational Psychology, vol. 73, pp. 485- 